\section{JURNAL ABDIMAS

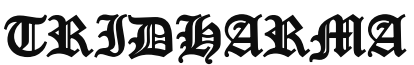

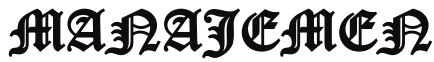

P-ISSN 2715-7105, E-ISSN 2716-070X

Jurnal ABDIMAS Vol. 1,No.2, Mei 2020, Hal (125-129)

@Prodi Manajemen Fakultas Ekonomi Universitas Pamulang

Email: abdimasjurnal.unpam@gmail.com Telp: (021) 741-2566

\title{
MOTIVASI MENABUNG PADA SISWA MTS MATHLAUL ANWAR PAMULANG - TAANGERANG SELATAN
}

\author{
Nina Shabrina ,Nani Rusnaeni, Sunanto, Asep Sulaeman,Nurismalatri \\ DosenEkonomi Fakultas Ekonomi Universitas Pamulang \\ Email nina.shabrina85@gmail.com, dosen00425@unpam.ac.id, \\ dosen00996@unpam.ac.id
}

\begin{abstract}
ABSTRAK
Pengabdian Kepada Masyarakat (PKM) merupakan bagian integral dari Tri Dharma Perguruan Tinggi yang dalam pelaksanaannya tidak terlepas dari dua dharma yangl ainnya, serta melibatkan segenap sivitas akademika :dosen,mahasiswa, tenaga kependidikan serta alumni. Melalui PKM sivitas akademik dapat hadir ditengahtengah masyarakat.

Melihat lokasi kampus yang tidak jauh dengan lokasi MTS Mathlaul Anwar, maka sudah menjadi kewajiban bagi Universitas Pamulang (Unpam) untuk ikut serta membantu berbagai persoalan yang dihadapi masyarakat baik yang dekat maupun yang jauh.

Ilmu Manejemen Keuangan khususnya Pengelolaan keuangan berkaitan dengan cara mencari tahu tentang pengelolaan dana secara sistematis, sehingga Manajemen keuangan bukan hanya penguasaan kumpulan pengetahuan saja tetapi juga merupakan proses penemuan. Permasalahan yang timbul yaitu tidak adanya media pembelajaran yang memadai untuk menjelaskan suatu konsep. Pembelajaran yang efektif . Namun kebanyakan sekolah masih merasakan kurangnya sarana dan prasarana tersebut.informasi masih cukup sulit didapatkan.Hal ini akan mempersulit masyrakat dalam memahami konsep,jadi penyuluh harus kreatif dan inovatif.

PKM dengan judul: "MOTIVASI MENABUNG PADA SISWA"secara umum berjalan dengan lancar dan tertib. Masyarakat antusias dalam menyimak penjelasan materi yang diberikan.
\end{abstract}

\section{Kata Kunci:Motivasi, menabung}

\section{ABSTRAC}

Community Service (PKM) is an integral part of the Tri Dharma of Higher Education which in its implementation is inseparable from the other two dharmas, and involves all academics: lecturers, students, education staff and alumni. Through PKM the academic community can be present in the midst of the community.

Seeing the location of the campus which is not far from the location of MTS Mathlaul Anwar, it has become an obligation for the University of Pamulang (Unpam) to participate in helping various problems faced by the community both near and far.

The science of Financial Management in particular financial management is related to how to find out about managing funds systematically, so that financial management is not only the mastery of a collection of knowledge but also a process of discovery. The problem that arises is the absence of adequate learning media to explain a concept. Effective learning. However, most schools still feel the lack of facilities and infrastructure. information is still quite difficult to obtain. This will make 


\section{JURNAL ABDIMAS

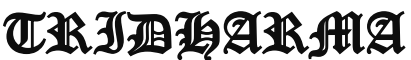

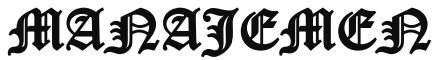

P-ISSN 2715-7105, E-ISSN 2716-070X

Jurnal ABDIMAS Vol. 1,No.2, Mei 2020, Hal (125-129)

@Prodi Manajemen Fakultas Ekonomi Universitas Pamulang

Email: abdimasjurnal.unpam@gmail.com Telp: (021) 741-2566

it difficult for the community to understand the concept, so extension workers must be creative and innovative.

PKM with the title: "SAVE MOTIVATION TO STUDENTS" in general went smoothly and in an orderly manner. the public was enthusiastic in listening to the explanation of the material provided.

\section{Keywords: motivation, saving}

\section{PENDAHULUAN}

Motivasi menabung memegang peranan penting dalam diri siswa karena dapat menumbuhkan gairah, merasa senang, dan semangat untuk menabung. Siswa yang mempunyai motivasi menabung yang kuat akan melakukan aktivitas-aktivitas menabung, karena motivasi menabung ini adalah dorongan atau daya gerak yang tumbuh di dalam diri siswa untuk melakukan aktivitas menabung tersebut. Oleh karena itu motivasi menabung ini perlu ditumbuhkembangkan di dalam diri siswa agar siswa terdorong atau tergerak untuk menabung. Motivasi menabung pada siswa ini dapat menanamkan kebiasaan hidup berhemat, tidak boros, memperoleh kesenangan dan kepuasan diri, dapat membeli barang-barang konsumsi yang diinginkan. Adapun motivasi menabung siswa yang penulis maksud adalah motivasi menabung siswa di sekolah. Menabung yang dilakukan siswa di sekolah diharapkan siswa dapat menyimpan uang yang diperolehnya dari orang tua yang bisa digunakan untuk membeli keperluan-keperluan sekolah. Namun demikian tentu tergantung juga kepada seberapa jumlah uang belanja yang diterima oleh siswa dari orang tuanya, apakah dapat memenuhi hasrat siswa untuk menabung. Hal ini sesuai dengan apa yang dikemukakan oleh Sukwiaty bahwa konsumsi rumahtangga memiliki hubungan yang erat dengan pendapatan yang dapat dibelanjakan.Motivasi menabung siswa di MTS Mathlaul Anwar cukup tinggi prosentasenya, hal ini terbukti dengan semakin meningkatnya jumlah siswa yang menabung setiap tahunnya. Keinginan ini didorong oleh hasrat yang tinggi dari siswa untuk berhemat, sehingga siswa rela mengurangi jatah belanja untuk konsumsi asalkan dapat menabung.

\section{RUMUSAN MASALAH}

Persoalan yang dihadapi oleh siswa MTS Mathlaul Anwar dalam penulisan proposal kegiatan dan surat menyurat adalah sebagai berikut ini:

1. Bagaimana menumbuhkan Motivasi menabung pada siswa?

2. Apa faktor yang mempengaruhi motivasi menabung siswa di sekolah?

\section{TUJUAN PELAKSANAAN}

Tujuan umum dari kegiatan pengabdian kepada masyarakat ini adalah:

1. Memberikan informasi terkait tentang motivasi menabung pada siswa

2. Memberikan informasi tentang factor yang mempengaruhi siswa menabung.

\section{TINJAUAN PUSTAKA}

\section{PengertianMotivasi}

Pengertian motivasi dari segi taksonomi, motivasi berasal dari kata "motive" dalam bahasa Inggris, yang artinya bergerak. Berbagai hal yang biasanya terkandung dalam berbagai defenisi tentang motivasi antara lain adalah keinginan, harapan, kebutuhan, tujuan, sasaran, dorongan dan insentif. Suatu motif adalah keadaan kejiwaan yang mendorong, mengaktifkan atau menggerakkan dan motif itulah yang mengarahkan dan menyalurkan perilaku, sikap, dan tindak tanduk seseorang yang selalu dikaitkan dengan pencapaian tujuan, baik tujuan organisasi maupun tujuan pribadi masingmasing anggota organisasi. 


\section{JURNAL ABDIMAS

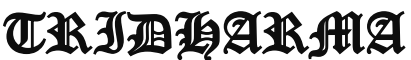

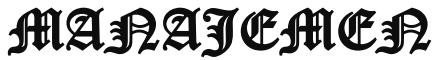

P-ISSN 2715-7105, E-ISSN 2716-070X

Jurnal ABDIMAS Vol. 1,No.2, Mei 2020, Hal (125-129)

@ Prodi Manajemen Fakultas Ekonomi Universitas Pamulang

Email: abdimasjurnal.unpam@gmail.com Telp: (021) 741-2566
Motivasi adalah faktor yang mendorong orang untuk bertindak atau berperilaku dengan cara tertentu; proses motivasi mencakup: (a) Pengenalan dan penilaian kebutuhan yang belum dipuaskan, (b) Penentuan tujuan yang akan memuaskan kebutuhan, dan (c) Penentuan tindakan yang diperlukan untuk memuaskan kebutuhan.7 Berdasarkan pendapat para ahli di atas dapat disimpulkan bahwa tidak ada motivasi jika tidak dirasakan adanya kebutuhan dan kepuasan serta ketidakseimbangan. Rangsangan terhadap hal termaksud akan menumbuhkan tingkat motivasi, dan motivasi yang telah tumbuh akan merupakan dorongan untuk mencapai tujuan pemenuhan kebutuhan atau pencapaian keseimbangan. Motivasi merupakan suatu dorongan kebutuhan dari dalam diri guru yang perlu dipenuhi agar guru tersebut dapat menyesuaikan diri terhadap lingkungannya, sedangkan motivasi adalah kondisi yang menggerakkan guru agar mampu mencapai tujuan dari motifnya.

\section{PengertianMenabung}

Menabung merupakan suatu aktivitas guna memenuhi suatu kebutuhan yaitu jaminan akan materi. Menabung merupakan kegiatan atau aktivitas yang memerlukan adanya keinginan dalam diri seseorang untuk menyisihkan dan menyimpan uangnya di bank. Menabung memerlukan minat agar perilakunya terarah pada aktivitas tersebut (menabung).Menabung merupakan proses menyimpan uang yang berorientasi untuk tujuan kebutuhan secara spesifik, misalnya untuk pendidikan anak, memiliki rumah atau persiapan pensiun.

Kecenderungan menabung dibedakan menjadi kecenderungan menabung marginal atau marginal propensity to save (MPS) yaitu perbandingan antara pertambahan tabungan dengan pertambahan pendapatan disposibel dan kecenderungan menabung rata-rata atau avarege propensity to save (APS) adalah perbandingan antara jumlah tabungan dengan jumlah pendapatan disposibel.19
Terdapat dua konsep dalam fungsi tabungan, yaitu Avarege Propensity to Save (APS) dan Marginal Propensity to Save (MPS).

\section{METODE PELAKSANAAN}

Persoalan yang dihadapi oleh Siswa di MTs Matlaul Anwar Pamulang adalah banyak siswa yang masih belum memahami minat menabung. Adapun permasalahan tersebut dapat dicarikan solusinya sebagai berikutini: Berdasarkan uraian masalah yang dihadapi oleh mitra, maka disepakati bahwa masalah utama yang dihadapi oleh mitra adalah siswa masih belum begitu memahami tentang motivasi menabung. Untuk mencapai keberhasilan pengabdian, maka diperlukan partisipasi yang baik oleh mitra. Bentuk partisipasi mitra antara lain:

a. Mendukung secara penuh kegiatan pengabdian.

b. Memberikan data terkait dengan hambatan yang dihadapi untuk focus dalam belajar.

c. Memberikan masukan tentang bagaimana meningkatkan kesadaran menabung.

d. Mempelajari dan mengaplikasikan materi-materi yang telah diberikan.

e. Berkoordinasi secara aktif selama kegiatan pengabdian.

Sebagai upaya untuk menilai apakah penyuluhan yang dilakukan telah diaplikasikan atau belum oleh mitra dan sejauh mana pelatihan dapat berpengaruh terhadap perkembangan dalam menulis proposal kegiatan dan surat menyurat maka perlu dilakukan evaluasi.Evaluasi dilakukan dengan mendatangi guru dan menanyakan apakah siswa memahami betul tentang motivasi menabung.

\section{HASIL DAN PEMBAHASAN}

Berdasarkan hasil pembahasan sebelumnya,maka dapat ditarik suatu kesimpulan terhadap hasil penelitian ini bahwa secara garis besar motivasi menabung bagi Siswa MTS Mathlaul 


\section{JURNAL ABDIMAS

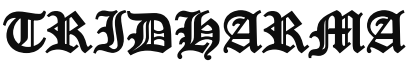

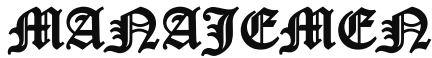

P-ISSN 2715-7105, E-ISSN 2716-070X

Jurnal ABDIMAS Vol. 1,No.2, Mei 2020, Hal (125-129)

@ Prodi Manajemen Fakultas Ekonomi Universitas Pamulang

Email: abdimasjurnal.unpam@ gmail.com Telp: (021) 741-2566
Anwar dipengaruhi oleh motivasi intrinsic dan motivasi ekstrinsik.

Namun pada umumny amotivasi intrinsic lebih mendominasi dorongan menabung bagi Siswa MTS Mathlaul Anwar.Artinya motivasi atau dorongan menabung bagi Siswa MTS Mathlaul Anwa rdidasari oleh motivasi intrinsik (minat menabung, Sikap menabung dan Harapan menabung).Dengan kata lain factor utama yang mendorong dorongan menabung bagi Siswa MTS Mathlaul Anwar adalah berasal dari dalam diri para siswa sendiri yaitu minat menabung, Sikap menabung dan Harapan dalam menabung. Factor-faktor yang mempengaruhi motivasi menabung padasiswa MTS Mathlaul Anwar diantaranya adalah :

\section{Minat menabung}

Minat adalah kecenderungan yang menetap untuk memperhatikan dan mengenang beberapa aktivitas.seseorang yang berminat terhadap suatu aktivitas akan memperhatikan aktivitas itu secara konsisten denganrasa senang. Dengan kata lain, minat adalah suatu rasa suka dan keterikatan pada suatu hal atau aktivitas, tanpa ada yang menyuruh. Pengertian lain tentang minat adalah suatu rasa lebih suka dan rasa keterikatan pada suatu hal atau aktivitas, tanpa ada yang meyuruh. Minat pada dasarnya adalah penerimaan akan suatu hubungan antara diri sendiri dengan sesuatu diluar diri. Semakin kuat atau dekat hubungan tersebut, semakin besar minatnya . Penelitian di Inggris menyatakan bahwa motivasi seorang membuka bisnis adalah 50\% ingin mempunyai kebebasan dengan berbisnis sendiri, hanya $18 \%$ menyatakan ingin memperoleh uang dan $10 \%$ menyatakan jawaban membuka bisnis untuk kesenangan, hobi, tantangan atau kepuasan pribadi dan melakukan kreativitas.Uraian di atas tentang minat dapat diartikan dengan kecenderungan yang menetap untuk memperhatikan dan mengenang beberapa aktivitas. Minat dalam aspek ini diartikan dengan: 1) Rasa senang atau suka terhadap manfaat menabung 2) Rasa keterikatan terhadap manfaat menabung

2. Sikap

Sikap merupakan kesiapan mental untuk berbuat, dan karena itu, dapat dipergunakan untuk meramal perilakunya. Sikap dapat berkembangmelalui pengalaman langsung dan komunikasi antara perseorangan. Melalui proses demikian, keyakinan berkembang atau berubah, dan disimpan dalam memori ingatan. Pengertian sikap dalam Kamus Besar Bahasa Indonesia Edisi Ketiga mengartikan bahwa sikap dapat diartikan dengan suatu perbuatan yang berdasarkan pada pendirian dan keyakinan.25 sikap diartikan sebagai kesiapan pada seseorang untuk bertindak secara tertentu. Sikap dapat bersifat positif, dan dapat pula bersifat negatif. Dalam sikap positif, kecenderungan tindakan adalah mendekati, menyenangi, mengharapkan obyek tertentu: sedangkan dalam sikap negatif terdapat kecenderungan untuk menjauhi, menghindari, membenci, tidak menyukai obyek tertentu.Aspek sikap itu sendiri dalam penelitian ini dibagi dalam: 1) Sikap terhadap menabung itu sendiri 2) Sikap meyakini terhadap menabung disekolah 3. Harapandalammenabung

Harapan adalah kuatnya kecendrungan seseorang bertindak dengan cara tertentu yang akan dikuti oleh suatu hasil tertentu dan pada daya tarikdari hasil itu bagi orang yang bersangkutan. Atau dengan cara lain dapat didefenisikan sebagai suatu keinginan untuk menghasilkan sesuatu karya pada waktu tertentu tergantung pada tujuan-tujuan khusus orang yang bersangkutan dan pada persepsi orang tersebut tentang nilai suatu prestasi kerja sebagai wahana untuk mencapai tujuan tersebut.26 Harapan berkaitan dengan perilaku seseorang dan daya tarik dari hasil bagi orang bersangkutan. Sebagai contoh seseorang menabung karena menginginkan bonus yang diberikan oleh pihak yang menginvestasikan dananya atau menginginkan agar dananya bisa terkumpul agar dapat digunakan ketika 


\section{JURNAL ABDIMAS

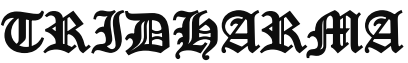

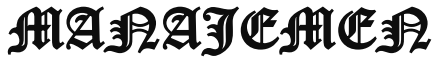

P-ISSN 2715-7105, E-ISSN 2716-070X

Jurnal ABDIMAS Vol. 1,No.2, Mei 2020, Hal (125-129)

@Prodi Manajemen Fakultas Ekonomi Universitas Pamulang

Email: abdimasjurnal.unpam@gmail.com Telp: (021) 741-2566 masa yang sulit. Dapat ditarik pengertian bahwa harapan terhadap lembaga penyimpan uang adalah kuatnya kepercayaan masyarakat dengan dengan lembaga penyimpan uang. Harapan orang tua direalisasikan dalam bentuk perilaku yang mendukung kelancaran kegiatan pendidikan di sekolah anaknya. Aspek harapan dalam penelitian ini dibagi dalam: 1) Aspek daya tarik dalam menabung 2) Aspek yang diharapkan dalam menabung

\section{KESIMPULAN DAN SARAN}

Kesimpulan

Dari motivasi menabung ini kalian bisa menghasilkan barang-barang yang kalian butuhkan dan yang kalian inginkan misalnya seperti menabung untuk membeli mobil, bayar uang sekolah, membeli rumah dan masih banyak lagi. Memang menabung itu membutuhkan sebuah proses yang sangat panjang tapi setelah proses itu tercapai kalian pasti akan menikmati hasil dari menabung tersebut. Kita juga harus tau bahwa menabung itu juga membutuhkan sebuah target, seperti apa targetnya? Targetnya adalah memakai cara yang cerdas atau smart, dapat di jangkau dan memiliki timing yang jelas. Dengan meningkatkan motivasi ini kalian harus mempunyai target yang ingin kalian tabung setelah itu kalian akan bisa menjalankan program menabung ini.

\section{DAFTAR PUSTAKA}

A. A Mangkunegara, Manajemen Sumber Daya Manusia, Bandung, Resdakarya, 2007)

A. Usmara, Motivasi Kerja, Yogyakarta, Asmara Book, 2006

Alam S, Jakarta: Esis, 2007
Buchari Alma, (1999). Kewirausahaan, Bandung, Alfabeta

Bari'ah, dkk, Hubungan antara Kualitas Layanan Bank dengan Minat Menabung Nasabah PT BRI Kantor Cabang Ungaran, Semarang, Universitas Diponegoro Depdikbud, Kamus Besar Bahasa Indonesia, edisi ketiga, Jakarta, Balai Pustaka, 2002

Depdiknas, Undang-Undang Sistem Pendidikan Nasional, Jakarta, Depdiknas, 2008

\section{DOKUMENTASI FOTO KEGIATAN}
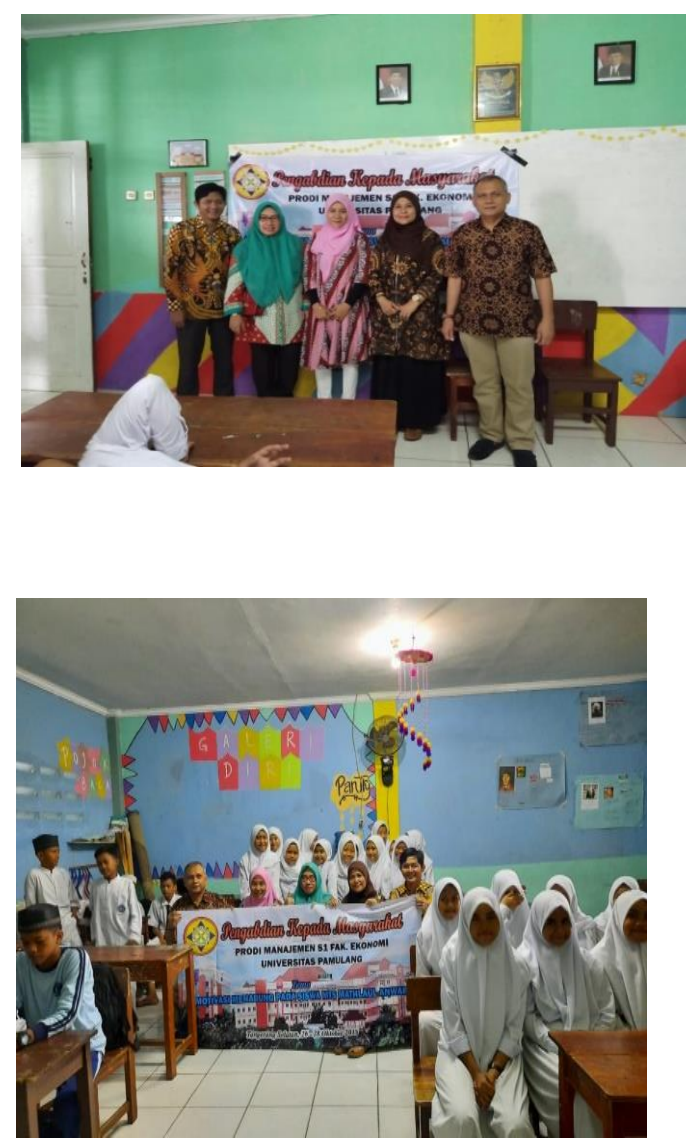